\title{
SLPI and AnxA2 expression in neoplasm-free palatine tonsils is associated with smoking habit of individuals
}

\author{
ELGAR S. QUABIUS ${ }^{1,2}$, BERIT BÖGERSHAUSEN $^{3 *}$, LUKAS GETZIN $^{1 *}$, TIBOR GÖRÖGH $^{1}$, \\ MAXIMILIAN P. GEBHARD ${ }^{4}$, ANNA S. HOFFMANN ${ }^{4,5}$ and MARKUS HOFFMANN ${ }^{1}$ \\ ${ }^{1}$ Department of Otorhinolaryngology, Head and Neck Surgery, and ${ }^{2}$ Institute of Immunology, \\ Christian-Albrechts University, D-24105 Kiel; Departments of ${ }^{3}$ Otorhinolaryngology and ${ }^{4}$ Pathology, \\ University of Schleswig-Holstein, D-23538 Lübeck; ${ }^{5}$ Department of Oto-Rhino-Laryngology, Head and Neck Surgery, \\ University Medical Centre Hamburg-Eppendorf, D-20246 Hamburg, Germany
}

Received February 26, 2017; Accepted June 6, 2017

DOI: $10.3892 /$ mco.2017.1343

\begin{abstract}
In order to confirm the inverse correlation between secretory leucocyte protease inhibitor (SLPI) expression, and human papillomavirus (HPV) infection previously observed in head and neck squamous-cell carcinoma, the present study retrospectively investigated the association between SLPI and Annexin A2 (AnxA2) expression, and HPV status in non-neoplastic chronic tonsillitis $(\mathrm{n}=118)$, and tonsillar hyperplasia $(n=96)$ tissue. We hypothesised that smoking induces the upregulation of SLPI, resulting in reduced binding of HPV to AnxA2, a known modulator of HPV entry into the cell. SLPI and cyclin-dependent kinase inhibitor $2 \mathrm{~A}\left(\mathrm{p} 16^{\mathrm{INK} 4 \mathrm{~A}}\right)$ protein expression was measured using immunohistochemistry in 214 specimens; SLPI and AnxA2 gene expression was measured using reverse transcription-quantitative polymerase chain reaction in 213 cases; and DNA was isolated from all the specimens to determine HPV status. The association between the results of the aforementioned analyses and the smoking habits of patients was analysed. The samples were HPV-negative. p16 ${ }^{\mathrm{INK} 4 \mathrm{~A}}$ expression demonstrated moderate and strong staining in 38 , and 0 cases, respectively. SLPI expression presented negative, weak and moderate signals in 163,45 , and 6 cases, respectively. A positive correlation was identified between smoking and SLPI $(\mathrm{P}=0.0001)$. Gene expression analysis $(n=213)$ revealed that smoking $(n=48)$ resulted in a significant increase in SLPI and AnxA2 expression. A significant positive correlation between AnxA2 and
\end{abstract}

Correspondence to: Dr Markus Hoffmann, Department of Otorhinolaryngology, Head and Neck Surgery, Christian-Albrechts University, Arnold-Heller-Street 3, Building 27, D-24105 Kiel, Germany

E-mail:mhoffmann@hno.uni-kiel.de

${ }^{*}$ Contributed equally

Key words: human papillomavirus, human papillomavirus, HNSCC, tonsillar cancer, secretory leucocyte protease inhibitor, Annexin A2
SLPI, indicating a surplus of AnxA2 in relation to SLPI, was exclusively identified in non-smokers. The data demonstrated that smoking results in increased SLPI and AnxA2 expression also in non-neoplastic tonsillar tissue. The observed surplus of AnxA2 in relation to SLPI identified exclusively in the tonsillar tissue of non-smokers indicates a higher possibility of a successful HPV infection of the tonsillar tissue of non-smokers, given the properties of AnxA2 to function as an infection modulator.

\section{Introduction}

In head and neck cancer (HNSCC) and specifically in tonsillar squamous cell carcinoma (TSCC) the mode of infection with human papillomaviruses (HPV) seems to be significantly influenced by the expression levels of two genes and their proteins, the quantitative association of which is dependent on the smoking habit of the patients. As shown previously (1-3), both the secretory leucocyte protease inhibitor (SLPI; an antiproteinase) and the membrane bound receptor Annexin A2 (AnxA2) showed higher expression levels in smokers in comparison to non-smokers. However, SLPI showed a clear surplus compared to AnxA2 in smokers vs. non-smokers whereas AnxA2 vs. SLPI showed a significant surplus in cases tested HPV-positive when compared to HPV-negative cases (1-3). Previous ex vivo data showed that SLPI expression in clinically healthy mucosa of the lower turbinates can be increased by incubation with nicotine (2). Additionally, in vitro studies showed that the cell entry of HPV is hindered when AnxA2 is blocked by SLPI in a cell culture model utilizing a cervix cancer cell line (4).

The hypothesis presented below is plausible and, may explain why non-smokers predominantly developing HPV-driven tumours whereas smokers suffer from, in terms of survival, less favourable HPV-negative tumours. Smoking induces a surplus of SLPI vs. AnxA2 in the mucosa of the head and neck, blocking AnxA2 as ligand for a successful HPV infection. Non-smoking individuals show an even amount of SLPI and AnxA2 or more likely even show a surplus of Anx A2 vs. SLPI, thus, giving HPV access to the ligand AnxA2 consecutively leading to cell entry and successful 
infection. Findings of previous studies have shown this correlation in 464 tissue specimens derived from 445 patients [HNSCC specimens, $n=397$; clinically normal mucosa, $n=57$ (from HNSCC patients, $\mathrm{n}=19$; from healthy individuals, $\mathrm{n}=38$ ); turbinates, $n=10](1-3)$. The results, with only a few exceptions, were statistical significant. In this context, however, it is noteworthy that it is assumed that an HPV infection occurs prior to carcinogenesis, i.e., in neoplasm-free mucosa of the upper aerodigestive tract. Since specifically TSCC are driven by $\mathrm{HPV}$-infections $(5,6)$ with $\mathrm{HPV}$ prevalence rates in this tumour entity of $30 \%$ to even $90 \%$ (7) of cases dependent on the geographical region the patients reside in $(6,8)$, the neoplasm-free tissue of the tonsils is of interest to test the described hypothesis.

Therefore, in the present study for the first time worldwide to the best of our knowledge, tissue specimens derived from 214 neoplasm-free palatine tonsils were tested for HPV- and p16 $6^{\mathrm{INK} 4 \mathrm{~A}}$-status, expression of SLPI and AnxA2, respectively, and the results were correlated with the smoking habit of the patients.

\section{Patients and methods}

Patients and sample preparation. Tissue samples of 214 non-neoplastic tonsillar tissue specimens with histopathologically confirmed chronic tonsillitis [CT; $n=118$ $(55.1 \%)]$ or tonsillar hyperplasia $[\mathrm{H} ; \mathrm{n}=96(44.9 \%)]$ were collected between 2013 and 2014. Of these, samples from 64 patients were obtained prospectively during surgery between 2013 and 2014 [CT; n=43 (67.2\%); H; n=21 (32.8\%)] at the Department of Otorhinolaryngology, Head and Neck Surgery, Christian-Albrechts-University (Kiel, Germany), after informed consent was obtained from the patients. The study was approved by the local Ethics Committee of the Christian-Albrechts-University (D509/13).

The tissue specimens were cut in halves, one part was snap-frozen for gene expression analysis and the other was FFPE-embedded for immunohistochemistry. The remaining 150 tissue specimens, all FFPE samples (75 CT and $75 \mathrm{H}$ ), were retrospectively retrieved form the archives of the Institute of Pathology, University Hospital Schleswig Holstein, Campus Lübeck. The original samples were obtained between 2009 and 2014 during surgery at the Department of Otolaryngology, Head and Neck Surgery, University Medical Center Schleswig-Holstein, University of Lübeck, Germany. Gene expression analysis was therefore performed on FFPE and fresh frozen material. Results were presented for the entire 214 patients and for the FFPE and fresh frozen samples, separately, to demonstrate homogeneity of results even when analyzing different sample materials.

Nucleic acid extraction, HPV-detection, cDNA synthesis and $q P C R$. From the retrospective FFPE material $(\mathrm{n}=150)$ DNA and RNA samples were simultaneously extracted from 4-6 consecutive $10 \mu \mathrm{m}$ sections using an ExpressArt Mag FFPE RNA+DNA ready kit (AmpTec GmbH, Hamburg, Germany) according to the manufacturer's protocol. For DNA- and RNA extraction of the prospectively collected fresh-frozen material $(\mathrm{n}=64) 25 \mathrm{mg}$ tissue was homogenized using a Precellys homogenizer (PeqLab, Erlangen,
Germany) and the $1.4 / 2.8 \mathrm{~mm}$ Ceramic kits in the presence of the AllPrep puffer (Qiagen, Hilden, Germany). DNA and RNA were then simultaneously isolated using the Allprep kit according to the manufacturer's protocol. Nucleic acid quantity and quality was analyzed using the Nanodrop 1000 (PeqLab) and the Tapestation 2200 (Agilent, Böblingen, Germany), respectively. HPV-DNA detection was performed by PCR using the primers GP5+/GP6+, as described previously (9). RNA (200 ng) was transcribed into cDNA using the TR cDNA synthesis kit (AmpTec GmbH). qPCR was performed as described previously (10). Primers for SLPI and AnxA2 were designed and used as described elsewhere (2). Primers for the housekeeping genes 18S rRNA, $\beta$-actin and b-2-microglobulin (B2M) were purchased from Promolgene (Berlin, Germany) and used according to the manufacturer's protocol. DNA integrity was analyzed using genomic B2M primers (Promolgene) and used according to the manufacturer's protocol.

Immunohistochemistry for SLPI and p16 ${ }^{I N K 4 A .}$ Paraffinembedded tissue specimens were cut $(4 \mu \mathrm{m})$ and stained with hematoxylin and eosin to detect tonsillar crypts. Areas containing such crypts were subjected to punch biopsies ( $2 \mathrm{~mm}$ in diameter) and were further processed for tissue microarray analysis (TMA) according to Kononen and co-workers (11). Immunohistochemical staining for SLPI and p16 ${ }^{\mathrm{INK} 4 \mathrm{~A}}$ expression was performed as described previously $(12,13)$. In brief: to assess SLPI and $\mathrm{p} 16^{\mathrm{INK} 4 \mathrm{~A}}$ protein levels the entire biopsies were analyzed (magnification, x200). The percentage of positive epithelial cells of the tonsillar crypts was determined and cases were assigned to one of the categories: negative $<5 \%$, weak $5-30 \%$, moderate $31-75 \%$ and strong $>75 \%$ of the cells were stained.

Statistical analysis. Immunohistochemical data were analyzed using two-sided Fisher's exact test (SPSS 20.0 software; IBM SPSS, Armonk, NY, USA). qPCR data were analyzed according to the $\Delta \Delta \mathrm{Cq}$ method (14) using the mean $\mathrm{Ct}$ value of the housekeeping genes. Fold changes of the expression levels were calculated as described previously (14) and the obtained values were used for statistical analysis (SPSS 20.0 software). Fisher's exact test was performed relating SLPI and p16 ${ }^{\mathrm{INK} 4 \mathrm{~A}}$ protein expression to HPV-positivity and smoking habit. $\mathrm{P}<0.05$ was considered statistically significant for all tests performed.

\section{Results}

Patient characteristics. Patient characteristics, i.e., age, sex, diagnosis and smoking habit, are given in Table I. Patients diagnosed with hyperplasia were significantly younger than those with chronic tonsillitis. In addition, the data presented show a significant correlation between smoking habit and diagnosis. Stratifying the data for an age cut-off of 18 years (the legal age to consume tobacco in Germany) revealed that the correlation between smoking habit and diagnosis was solely due to the large amount of non-smoking patients diagnosed with hyperplasia and who were $<18$ years $(n=93$ patients, representing $43.5 \%$ of the study population and $56.0 \%$ of the non-smoking patients). 


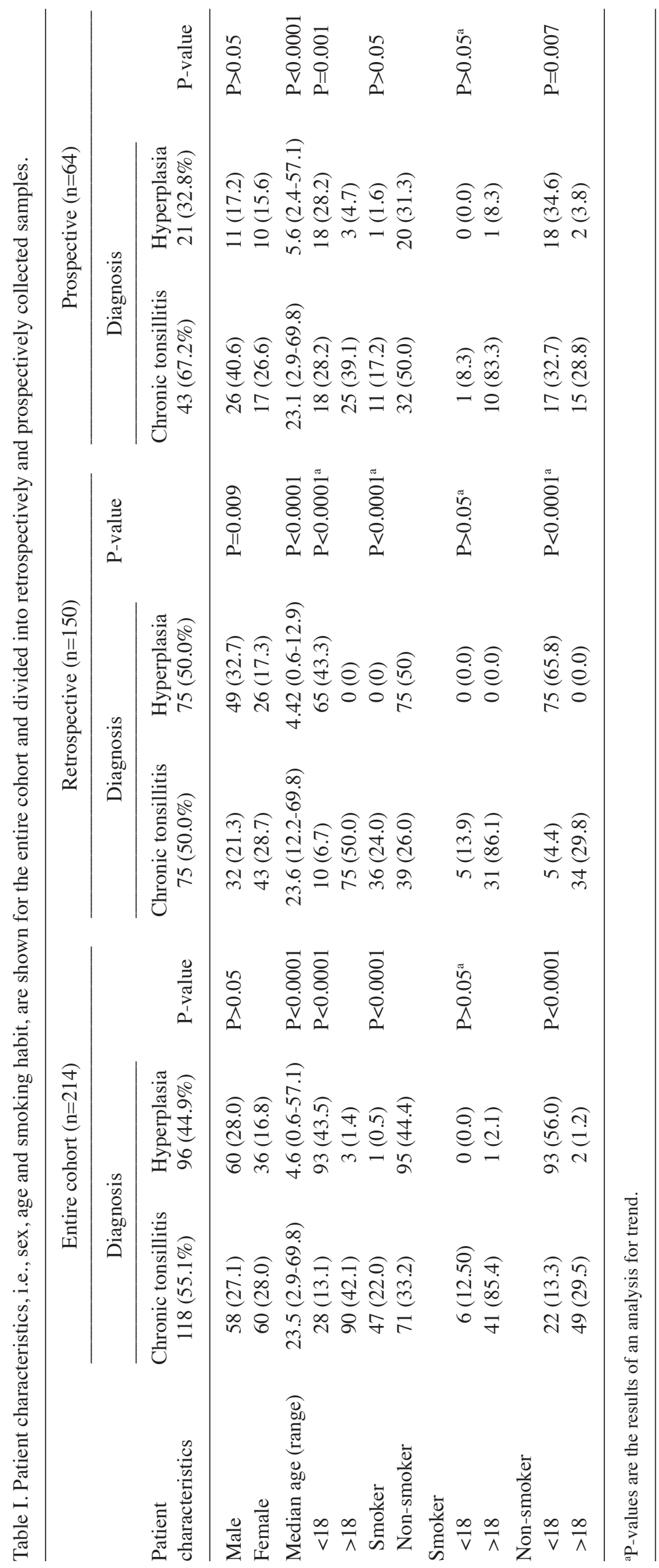



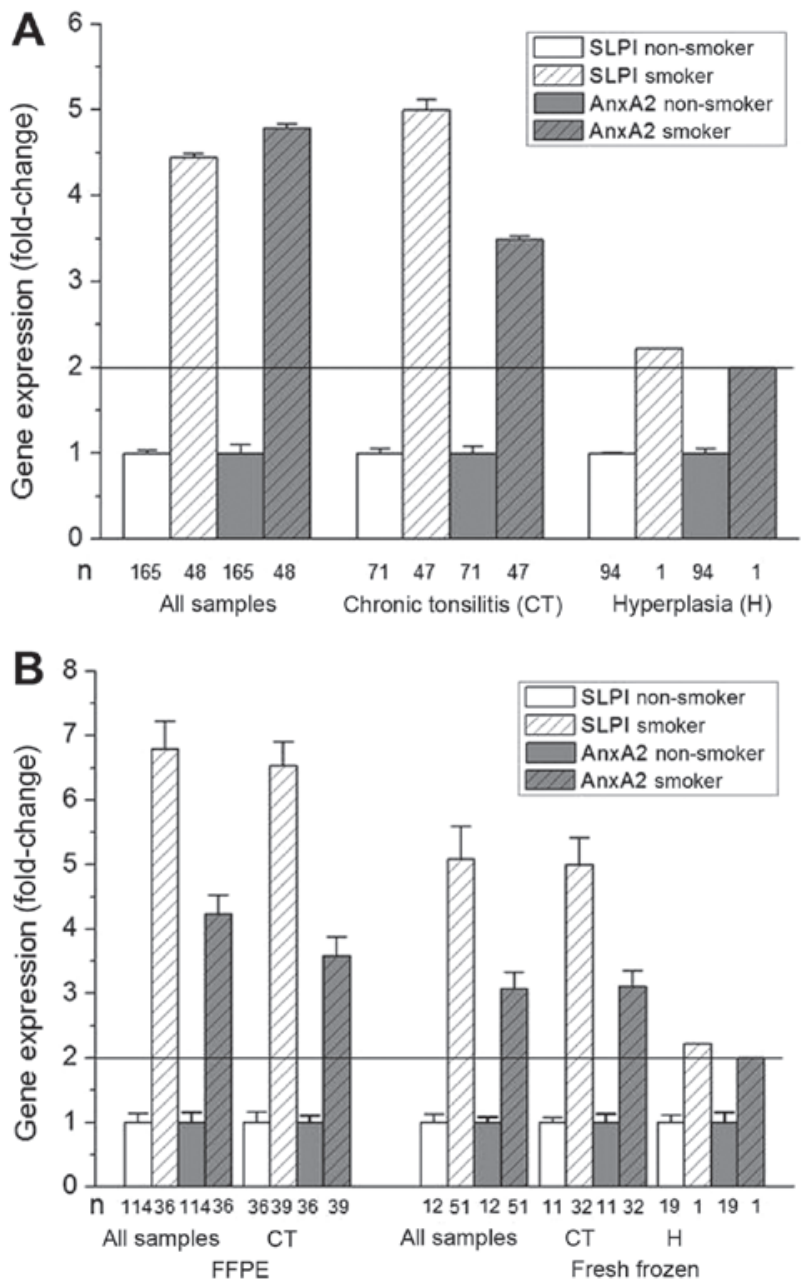

Figure 1. SLPI and AnxA2 gene expression. All teh samples and stratified for diagnosis only (A) and stratified first for sampling procedure and then for diagnosis (B) are shown. For all diagrams, $\Delta \Delta \mathrm{cq}$ values obtained in non-smoking individuals were set as 1 and fold changes in smoking individuals were calculated as described elsewhere (14). Dotted lines indicate 2-fold changes of gene expression level. As described previously, 2-fold changes in gene expression levels are considered statistically significant (14).

Gene expression of SLPI and AnxA2. Patients with chronic tonsillitis had a significantly higher SLPI gene expression levels than patients with hyperplasia (2.6-fold higher in the entire population; 2.01-fold in the fresh frozen and 2.6-fold in the FFPE samples). Similar results were obtained when analyzing AnxA2 gene expression. In the entire cohort, patients with chronic tonsillitis had 2.21-fold more AnxA2 than patients with hyperplasia. In the fresh-frozen material AnxA2 was 2.48-fold higher and in the FFPE samples 2.39-times more AnxA2 was measured.

The effect of smoking on SLPI and AnxA2 gene expression was then analyzed. As shown in Fig. 1A smoking resulted in significant increases in SLPI and AnxA2 gene expression. This increase was evident, not only when analyzing all samples but also when stratifying for diagnosis (Fig. 1A) and when stratifying for sample material and diagnosis (Fig. 1B). Of note, consistent results for SLPI- and AnxA2 gene expression levels were obtained when analyzing fresh frozen and FFPE material separately and stratified these for diagnosis. The observed effects were more pronounced for SLPI than for
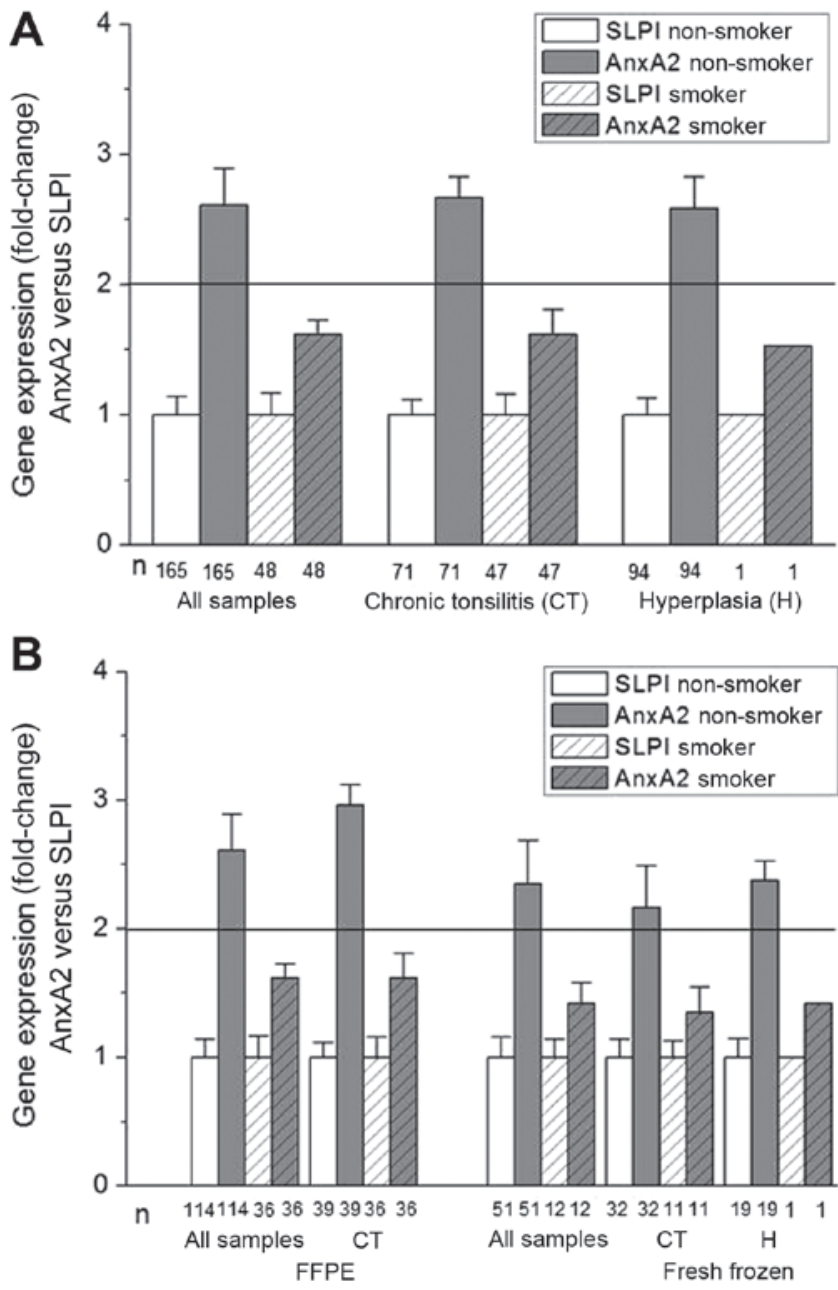

Figure 2. Comparison of AnxA2 and SLPI gene expression. To compare AnxA2 vs. SLPI gene expression levels, SLPI gene expression for each patient group was set as ' 1 '. Fold change expression levels of AnxA2 were then calculated as described elsewhere (14). (A) Results obtained in all the samples and stratified for diagnosis only. (B) The results shown were stratified first for sampling procedure and then for diagnosis. Dotted lines indicate 2 -fold changes of gene expression level. As described previously, 2-fold changes in gene expression levels are considered statistically significant (14).

AnxA2 gene expression. However, due to the relatively small amount of patients reporting a smoking habit, in particular in the group of patients with hyperplasia (only 1 smoker), the results need to be interpreted with caution.

To determine the association between SLPI and AnxA2 gene expression, the fold change of AnxA2 gene expression in relation to SLPI gene expression was calculated (Fig. 2). Again consistent results were obtained analyzing either all samples, all samples stratified for chronic tonsillitis or hyperplasia or analyzing the fresh-frozen and FFPE material separately and these were stratified for diagnosis. In all non-smoking patients AnxA2 gene expression was significantly higher than the SLPI gene expression. This was not the case in the group of patients reporting a smoking habit, where AnxA2 and SLPI gene expression were nearly equal (fold change levels $<2$ ).

Protein expression of SLPI. To corroborate SLPI gene expression by protein level expression of SLPI protein was measured by means of immunohistochemistry. The data were correlated with diagnosis and smoking habit of the patients. 


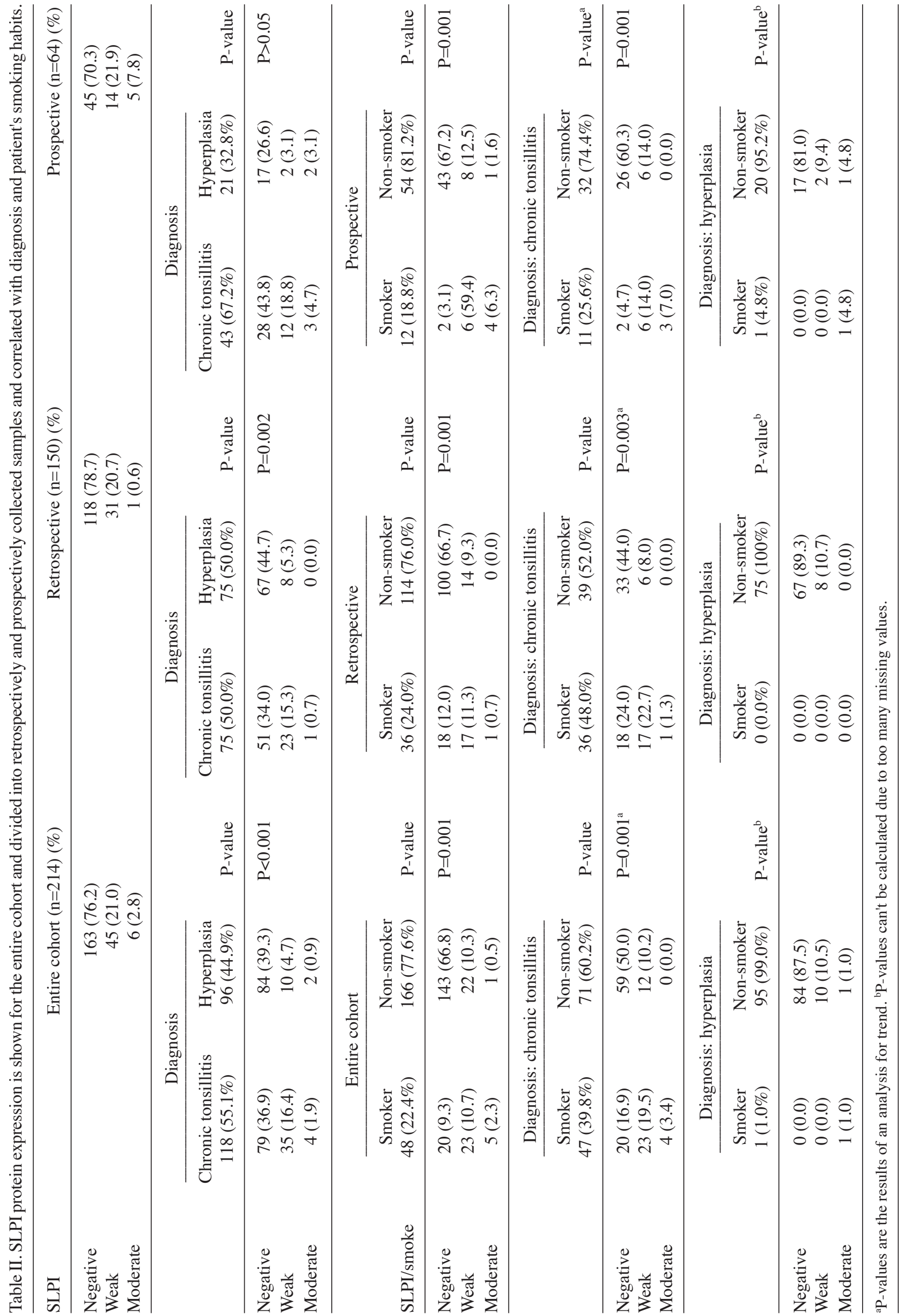


Overall none of the samples showed strong SLPI-expression ( $>75 \%$ of the epithelial cells of the tonsillar crypts being SLPI-positive) and the majority of the samples were classified as SLPI-negative ( $<5 \%$ of the epithelial cells of the tonsillar crypts being SLPI-positive). Nonetheless, the number of tissue specimens classified as weak or moderate was higher in the group of patients diagnosed with chronic tonsillitis than in the group of patients diagnosed with hyperplasia. This was true when analyzing the entire cohort and the retrospectively and prospectively samples separately, with the exception that, possible due to the smaller sample size, no significant differences were seen in the prospective samples. Correlation of SLPI protein expression with smoking habit showed in all groups that SLPI negativity was correlated with a negative smoking behavior. However, again due to the extremely small number of patients reporting a smoking habit, especially in the group of patients with hyperplasia $(n=1)$ these data need to be interpreted with caution (Table II).

HPV-status. HPV-DNA analysis was performed in all 214 biopsies. None of the samples showed any signal in the GP5+/GP6+PCR. However, all samples were positive in the $\mathrm{B} 2 \mathrm{M}-\mathrm{PCR}$, demonstrating DNA integrity. In addition, a positive control (a synthetic oligonucleotide of the HPV L1 gene, covered by the GP5+/GP6+ primers; Eurofins; Ebersberg Germany) was amplified in the GP5+/GP6+PCRs and resulted in the expected signals.

p16 ${ }^{\text {INK4A }}$ immunohistochemistry. Since $\mathrm{p} 16^{\mathrm{INK} 4 \mathrm{~A}}$ overexpression is frequently used as a surrogate marker for HPV positivity in HNSCC, immunohistochemistry for p16 ${ }^{\text {INK4A }}$ was performed and the results are shown in Table III. p16 ${ }^{\mathrm{INK} 4 \mathrm{~A}}$-expression showed negative, weak, and moderate reaction in a so-called patchy pattern in $20(9.3 \%), 156(72.9 \%)$, and $38(17.8 \%)$ cases. There was neither strong ( $>75 \%$ of cells positive) nor continuous immunostaining of basal keratinocytes. In addition, p16 ${ }^{\mathrm{INK} 4 \mathrm{~A}}$ expression was correlated with diagnosis (Table III). No significant correlation between protein expression and diagnosis was found.

\section{Discussion}

The results of this unique study investigating 214 tissue specimens derived from patients with tonsillar hyperplasia $(n=96)$ or chronic tonsillitis $(n=118)$ reveal that also in non-malignant tissue specimens of the tonsils there is a significant correlation between the patients' smoking habit and the expression levels of AnxA2 and SLPI, both showing significantly higher expression levels in smokers in comparison to non-smokers. These results were confirmed for SLPI on the protein level, showing that SLPI negativity is associated with a negative smoking history which holds true in all groups investigated. The additional findings regarding gene expression levels demonstrate that within the group of non-smokers AnxA2 shows a significant surplus when compared to SLPI whereas this ratio is approximately even in smokers. These findings corroborate the results shown for malignant tissue specimens derived from head and neck cancers as published, previously (1-3). Thus, the data of the present study are in line with our hypothesis described earlier in the present study as well as in previous studies (1-3), namely that both, AnxA2 and SLPI, may play a role in the mode of infection with human papillomaviruses in head and neck (HNSCC) and specifically tonsillar squamous cell carcinomas (TSCC) (1-3).

The described statistical significance regarding the correlation of AnxA2, SLPI, and smoking habit can be seen only in tests for trend for one single result when the entire study population is analysed and, however, for some results in the subgroup analysis (Tables I-III). The latter is due to the fact that the study included tonsillectomy patients who were previously diagnosed with tonsillar hyperplasia. As expected this specific subgroup of patients with tonsillar hyperplasia predominantly comprises children (median age, 4.6 years) with no smoking history leading to a significant imbalance between the subgroups chronic tonsillitis (median age, 23.5 years) and tonsillar hyperplasia when data are correlated with smoking habit. The authors, however, were aware of this fact ahead of the study and the reason for including cases with tonsillar hyperplasia was that SLPI is also involved in inflammation (15) present in chronic tonsillitis. To rule out such an inflammation caused bias, data of at least less inflamed tissue was needed, namely that of patients (children) with tonsillar hyperplasia not showing high-grade signs of inflammation. Against this backdrop and despite the small case numbers among the various subgroups it is, noteworthy that the majority of results specifically for gene expression analysis very clearly show statistical significance and this even in the subgroup of tonsillar hyperplasia, however, less significant than in the group of chronic tonsillitis.

Somewhat unexpected is the absence of any HPV-DNA in the tonsillar tissue analysed in the present study. Since in the literature a very low but still present HPV detection rate was described (16-18), it was assumed that at least two to four of these 214 cases would carry HPV-DNA, enough to further analyse the basic hypothesis of this study. In this context it is notable that the rate of HPV-DNA-positivity in oral rinses is reported to be approximately 7\% (19) and it now remains to be clarified which tissue harbours the HPV-DNA detected in oral gargle, when the tonsillar tissue is not. Palmer and co-workers reported on $0 \% \mathrm{HPV}$-positivity in non-malignant tonsillar tissue among a study population of less than 3,300 patients in the UK (20). The latter and our data question as already discussed by Franceschi and co-workers (18) whether or not the absence of HPV-DNA in non-neoplastic tonsillar tissue justifies invasive detection methods to detect HPV-infections in healthy individuals to identify precancerous lesions and possibly prevent carcinogenesis.

The immunohistochemical results for $\mathrm{p} 16^{\mathrm{INK} 4 \mathrm{~A}}$ excluded any early HPV-induced (premalignant) neoplasia. Table III shows that the vast majority of cases show weak staining whereas negativity or moderate staining occurs in approximately 10 and $20 \%$, respectively. The slightly higher expression pattern in chronic tonsillitis when compared to tonsillar hyperplasia can most likely also be attributed to inflammation processes in cases with chronic tonsillitis. Another possible explanation for the slightly, albeit not significant, higher $16^{\mathrm{INK} 4 \mathrm{~A}}$ expression pattern in patients with chronic tonsillitis may be due to the smoking habit of these patients since among the patients with chronic tonsillitis the proportion of smokers was significantly higher than in the group of patients with tonsillar hyperplasia. 


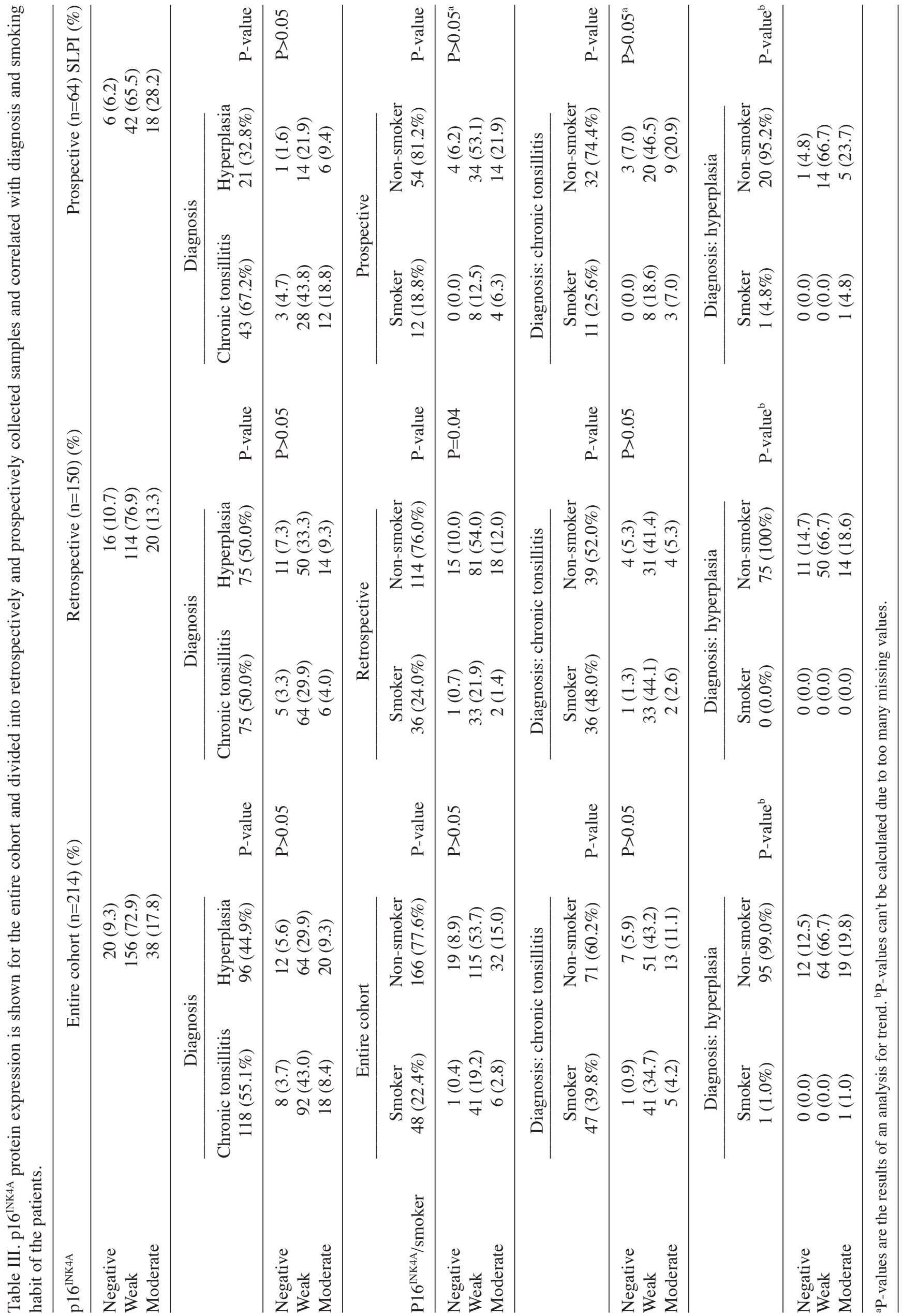


Since $\mathrm{p} 16^{\mathrm{INK} 4 \mathrm{~A}}$ is frequently used as a surrogate marker for HPV infection this observation is in agreement with the finding that HPV-induced HNSCC are often attributed to a negative smoking history of the patients (21).

In conclusion, despite the lack of an HPV-positive case the data shown in the present study are in agreement with previous studies regarding the correlation between SLPI- and AnxA2-expression and smoking habit of the patients. Smoking results in higher SLPI as well as AnxA2 expression with an even distribution of both parameters in smoking individuals whereas in non-smoking patients there is a significant surplus of AnxA2 in comparison to SLPI. Previous findings suggest that a surplus of AnxA2 in the mucosa increases the susceptibility of HPV infections while a surplus of SLPI seems to hinder successful HPV entry into the cells since SLPI blocks AnxA2 for HPV interaction. Despite the fact that HPV detection in non-malignant tonsillar tissue specimens identifies only very small numbers of HPV-positive cases, the results of the present study encourage further investigation of the basic hypothesis regarding SLPI-, AnxA2-expression, smoking habit and HPV status. Further knowledge regarding the mode of HPV cell entry may, not only contribute to the understanding of HPV infection and oncogenesis in head and neck cancer, but also contribute to the understanding of other virus infections with malignant potential such as EBV infections.

\section{Acknowledgements}

The authors would like to thank Gudrun Scherer and Hilke Clasen (Institute of Immunology, Kiel, Germany) for skilful technical assistance with immunohistochemistry and RNA-isolation, cDNA synthesis, (q)PCR, respectively. Special thanks goes to Ralph Pries and Maren Drenckhan (Department ORL, Head and Neck Surgery, UKSH, Campus Lübeck, Germany) for performing the tissue microarrays.

\section{References}

1. Hoffmann M, Quabius ES, Tribius S, Hebebrand L, Görögh T, Halec G, Kahn T, Hedderich J, Röcken C, Haag J, et al: Human papillomavirus infection in head and neck cancer: The role of the secretory leukocyte protease inhibitor. Oncol Rep 29: 1962-1968, 2013.

2. Quabius ES, Möller P, Haag J, Pfannenschmidt S, Hedderich J, Görögh T, Röcken C and Hoffmann M: The role of the antileukoprotease SLPI in smoking-induced human papillomavirus-independent head and neck squamous cell carcinomas. Int J Cancer 134: 1323-1334, 2014.

3. Quabius ES, Görögh T, Fischer GS, Hoffmann AS, Gebhard M, Evert M, Beule A, Maune S, Knecht R, Óvári A, et al: The antileukoprotease secretory leukocyte protease inhibitor (SLPI) and its role in the prevention of HPV-infections in head and neck squamous cell carcinoma. Cancer Lett 357: 339-345, 2015.

4. Woodham AW, Da Silva DM, Skeate JG, Raff AB, Ambroso MR, Brand HE, Isas JM, Langen R and Kast WM: The S100A10 subunit of the annexin A2 heterotetramer facilitates L2-mediated human papillomavirus infection. PLoS One 7: e43519, 2012.

5. Hoffmann M, Ihloff AS, Görögh T, Weise JB, Fazel A, Krams M, Rittgen W, Schwarz E and Kahn T: p16(INK4a) overexpression predicts translational active human papillomavirus infection in tonsillar cancer. Int J Cancer 127: 1595-1602, 2010.
6. Quabius ES, Haag J, Kühnel A, Henry H,Hoffmann AS, Görögh T, Hedderich J, Evert M, Beule AG, Maune S, et al: Geographical and anatomical influences on human papillomavirus prevalence diversity in head and neck squamous cell carcinoma in Germany. Int J Oncol 46: 414-422, 2015.

7. Mehanna H, Beech T, Nicholson T, El-Hariry I, McConkey C, Paleri V and Roberts S: Prevalence of human papillomavirus in oropharyngeal and nonoropharyngeal head and neck cancer-systematic review and meta-analysis of trends by time and region. Head Neck 35: 747-755, 2013.

8. Castellsagué X, Alemany L, Quer M, Halec G, Quirós B, Tous S, Clavero O, Alòs L, Biegner T, Szafarowski T, et al: HPV involvement in head and neck cancers: Comprehensive assessment of biomarkers in 3680 patients. J Natl Cancer Inst 108: djv403, 2016.

9. Remmerbach TW, Brinckmann UG, Hemprich A, Chekol M, Kühndel K and Liebert UG: PCR detection of human papillomavirus of the mucosa: Comparison between MY09/11 and GP5+/6+ primer sets. J Clin Virol 30: 302-308, 2004.

10. Quabius ES, Ossenkop L, Harder S and Kern M: Dental implants stimulate expression of Interleukin- 8 and its receptor in human blood-an in vitro approach. J Biomed Mater Res B Appl Biomater 100: 1283-1288, 2012.

11. Kononen J, Bubendorf L, Kallioniemi A, Bärlund M, Schraml P, Leighton S, Torhorst J, Mihatsch MJ, Sauter G and Kallioniemi OP: Tissue microarrays for high-throughput molecular profiling of tumor specimens. Nat Med 4: 844-847, 1998.

12. Cordes C, Häsler R, Werner C, Görögh T, Röcken C, Hebebrand L, Kast WM, Hoffmann M, Schreiber S and Ambrosch P: The level of secretory leukocyte protease inhibitor is decreased in metastatic head and neck squamous cell carcinoma. Int J Oncol 39: 185-191, 2011.

13. Klaes R, Friedrich T, Spitkovsky D, Ridder R, Rudy W, Petry U, Dallenbach-Hellweg G, Schmidt D and von Knebel Doeberitz M: Overexpression of p16(INK4A) as a specific marker for dysplastic and neoplastic epithelial cells of the cervix uteri. Int J Cancer 92: 276-284, 2001.

14. Pfaffl MW: A new mathematical model for relative quantification in real-time RT-PCR. Nucleic Acids Res 29: e45, 2001.

15. Majchrzak-Gorecka M, Majewski P, Grygier B, Murzyn K and Cichy J: Secretory leukocyte protease inhibitor (SLPI), a multifunctional protein in the host defense response. Cytokine Growth Factor Rev 28: 79-93, 2016.

16. Klingenberg B, Hafkamp HC, Haesevoets A, Manni JJ, Slootweg PJ, Weissenborn SJ, Klussmann JP and Speel EJ: p16 INK4A overexpression is frequently detected in tumour-free tonsil tissue without association with HPV. Histopathology 56: 957-967, 2010.

17. Rusan M, Klug TE, Henriksen JJ, Bonde JH, Fuursted K and Ovesen T: Prevalence of tonsillar human papillomavirus infections in Denmark. Eur Arch Otorhinolaryngol 272: 2505-2512, 2015.

18. Franceschi S, Combes JD, Dalstein V, Caudroy S, Clifford G, Gheit T, Tommasino M, Clavel C, Lacau St Guily J and Birembaut P; Study of Natural History of Human Papillomavirus Infection and Precancerous Lesions in the Tonsils (SPLIT): Deep brush-based cytology in tonsils resected for benign diseases. Int J Cancer 137: 2994-2999, 2015.

19. Kreimer AR, Johansson M, Waterboer T, Kaaks R, Chang-Claude J, Drogen D, Tjønneland A, Overvad K, Quirós JR, González CA, et al: Evaluation of human papillomavirus antibodies and risk of subsequent head and neck cancer. J Clin Oncol 31: 2708-2715, 2013.

20. Palmer E, Newcombe RG, Green AC, Kelly C, Noel Gill O, Hall G, Fiander AN, Pirotte E, Hibbitts SJ, Homer J and Powell NG: Human papillomavirus infection is rare in nonmalignant tonsil tissue in the UK: Implications for tonsil cancer precursor lesions. Int J Cancer 135: 2437-2443, 2014.

21. Gillison ML, D'Souza G, Westra W, Sugar E, Xiao W, Begum S and Viscidi R: Distinct risk factor profiles for human papillomavirus type 16-positive and human papillomavirus type 16-negative head and neck cancers. J Natl Cancer Inst 100: 407-420, 2008. 